\title{
Optimization Method for the Integration of Hybrid Energy Storage Systems in Industrial Applications
}

\author{
Irene Peláez \\ Dept.of Elec., Computer \& System Engineering \\ University of Oviedo \\ Gijón, Spain \\ pelaezirene.uo@uniovi.es
}

\begin{abstract}
This paper develops an optimization method for the integration of a hybrid energy storage system (HESS) considering different supercapacitors and three different forms of Li-Ion batteries: NMC (LiNiMnCo), LFP $\left(\mathrm{LiFePO}_{4}\right)$ and LTO $\left(\mathrm{Li}_{2} \mathrm{TiO}_{3}\right)$. The proposed method finds the proper demand side management (DSM) measures and optimizes the size of the HESS based on the profile selected and the electric tariff, finding the case where the net present value (NPV) is maximized. This method also evaluates which supercapacitor and battery chemistry better suit for each case. The proposed method allows to clearly evaluate not only the technical issues related with the performance of the system, but also the economical impact on the electric bill when integrating a HESS in an industrial application. This method will be also compared with the solution by only considering economical factors.
\end{abstract}

\section{INTRODUCTION}

Following the rapid declining cost in Li-Ion batteries due to economy of scale, it becomes a competitive technology in stationary applications. During decades, Lead-acid batteries have dominated this sector due to its low cost [1]. However, LiIon batteries have improved their features in terms of energy and power density, cycling and voltage level and makes them the most suitable technology for this kind of application. Compared to Lead-acid batteries, Li-Ion have a greater number of cycles that results in a technology with a lower cost per $\mathrm{kWh}$ [2]. Moreover, for long term applications, it is recommended to include supercapacitors in order to enlarge battery cycling and improve the overall performance of the HESS [3], [4].

The present work has been partially supported by the predoctoral grant programs Severo Ochoa and FPU for the formation in research and university teaching of Principado de Asturias PCTI-FICYT under the grant ID BP16133 and Spain MECD under the grant ID FPU16/06829. This work also was supported in part by the Research, Technological Development and Innovation Program Oriented to the Society Challenges of the Spanish Ministry of Economy and Competitiveness under grant ENE2016-77919-R and by the European Union through ERFD Structural Funds (FEDER). Finally, this work has been also supported by the government of Principality of Asturias, under IDEPA grant 2017 Thyssen SV-PA-17-RIS3-3.

\author{
Sara Saheed \\ Dept.of Elec., Computer \& System Engineering \\ University of Oviedo \\ Gijón, Spain \\ hazkialsarah.uo@uniovi.es
}

Industrial processes have a large potential for improving the efficient use of energy resources and reducing the electricity bill by means of HESS. DSM is one of the most suitable technique due to its advantages [5]. However, the use of HESS requires a deep analysis considering the associated costs, and so, optimizing its size is crucial. Literature have been more focused on optimizing the size of HESS used in transportation or renewable sources rather than industry. In this case, HESS aging takes a greater importance because they operate a longer time and each storage technology has to be thoroughly evaluated. This paper proposes to integrate the HESS by coupling it together with a power converter for the connection to the grid.

This paper examines hybrid solutions for a HESS based on batteries with different chemistry and supercapacitors. There are some toolboxes dealing with the performance of various technologies of HESS [6], [7], an other toolbox dealing with the optimization design of HESS and converter stages, like [8]. The contemplated method seeks to develop an integral methodology covering both technical and economical aspects. For that purpose, different batteries and supercapacitors devices are analysed. Furthermore, the impact of power losses on the overall system efficiency is also considered.

For the battery analysis, LTO, NMC and LFP chemistries are considered. Whereas NMC has the lowest price and highest energy density, it also has the lowest C-rate and number of cycles. On the other side, LTO is the most expensive and has the lowest energy density, but it achieves the highest current rate and number of cycles. Meanwhile, LFP features are in the middle of the previous two [9]. The analysis carried out in this paper will allow for selecting the battery chemistry better fitting the profile requirements.

Supercapacitors is the other technology used to support the storage system. It will be used under higher stress, so aging has to be analyzed under particular scrutiny. In comparison with battery-based storage systems, supercapacitors have a 
higher number of cycles. The main factor that affect their lifespan is temperature. Depth-of-discharge (DoD) and charge voltage also contribute on their capacitance fade [3]. The rule of thumb states that every $10^{\circ} \mathrm{C}$ increased in working temperature, supercapacitors degrades 1.2 times faster. It is recommended to use supercapacitors above $50 \%$ of its stateof-charge (SoC) to enlarge its life and not keep the voltage high during floating conditions $(0.1 \mathrm{~V}$ increase is equivalent to a $10^{\circ} \mathrm{C}$ increase) [3], [10]. The end-of-life (EoL) is defined to occur either when it reaches $80 \%$ of its capacitance or doubles its internal resistance [11].

The impact of the efficiency on the converter topology is also evaluated. Depending on the operating point and the input voltage, the efficiency of the converter varies [12]. A general method to evaluate the efficiency of the converter based on the rated power and voltage is implemented. A Multi-port Power Electronic Interface (MPEI) converter is considered for the integration of the HESS.

Finally, once the performance constrains are implemented in the method, it is obtained the combination of HESS, converter and DSM measures that achieves higher revenues for a determined profile.

This paper is organized in three main sections. Section II presents the process analysed, the models used for each technology and the tariff considered for the analysis. Section III evaluates the data signal processing, provides straightforward method to allocate the power between supercapacitors and batteries based on their cost, and finally, the optimization method proposed is presented. In Section IV, the results are given for the processes considered.

\section{TECHNO-ECONOMICAL ANALYSIS}

The proposed methodology is based on an analysis of the power allocation of experimentally collected consumption data, considering the efficiency of the storage devices and the power converter. The optimization method uses the NPV value as the figure of merit.

\section{A. Process description}

The aim of this paper is to evaluate the feasibility of reducing the industrial process electricity bill by integrating a HESS. Three different load profiles from the steel industry are evaluated (Fig. 1). They share in common to be nearly-periodic non-stop processes, and the last one involves regenerative braking.

The ultimate goal of the HESS is to reduce the cost of the electricity in industrial process from the user side. Three different approaches are considered: 1) reduction in the allocated power, 2) energy shifting to lower cost periods and 3) efficiency improvement. These is implemented by the following DSM measures: 1) peak shaving, 2) use of regenerative braking when available and 3) load levelling.

\section{B. Energy Storage Hybridization}

Design of HESS shall be based on an optimization approach based on economical constraints. The considered batteries and supercapacitors systems are collected in Table I and II.

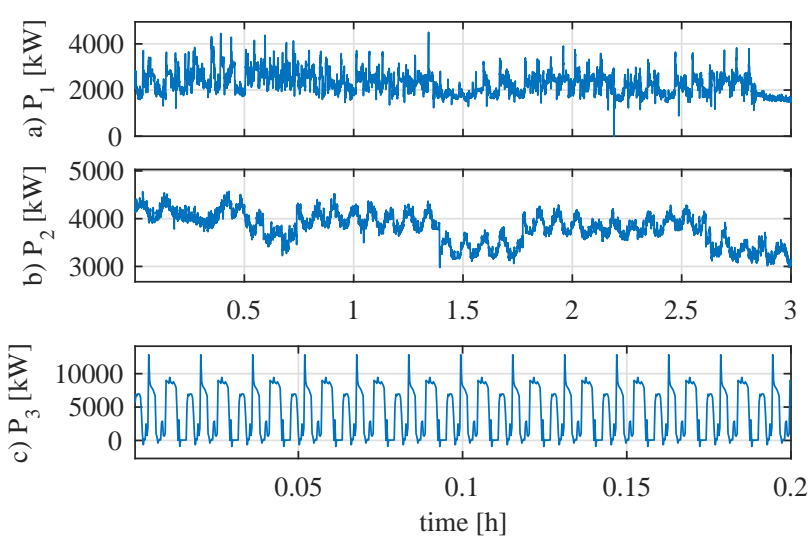

Fig. 1. Profiles $P-1, P-2$ and $P-3$ which correspond to Picking, Galvanizing and rolling mill processes respectively.

TABLE I

PARAMETERS OF THE BATTERIES.

\begin{tabular}{|c|c|c|c|c|c|}
\hline Bat & & NMC & $\mathrm{LFP}_{c y l}$ & LTO & $\mathrm{LFP}_{\text {pris }}$ \\
\hline $\mathbf{P}_{r}[\mathbf{k W}]$ & & 347 & 608 & 549 & 103 \\
\hline $\mathbf{E}_{r}[\mathbf{k W h}]$ & & 115 & 101 & 69 & 52 \\
\hline cycles $^{1}$ & & 3800 & 7300 & 15100 & 5000 \\
\hline \multirow{2}{*}{ Installation Cost } & {$[€ / \mathrm{kWh}]$} & 600 & 1000 & 2000 & 625 \\
\hline & {$[€ / \mathrm{kW}]$} & 265 & 275 & 321 & 316 \\
\hline $\mathbf{E}_{\text {cost }}^{2}[€ / \mathbf{k W h}]$ & & 0.20 & 0.17 & 0.17 & 0.16 \\
\hline Num. cells & & 6480 & 15360 & 7200 & 90 \\
\hline Num. of modules & & 135 & 320 & 150 & 6 \\
\hline Num. cells/module & & 48 & 48 & 48 & 15 \\
\hline
\end{tabular}

${ }^{1}$ Number of cycles using a $80 \%$ of DoD.

${ }^{2} \mathrm{E}_{\text {cost }}$ is the cost considering the battery lifespan- (1).

$$
E_{\text {cost }}[€ / k W h]=\frac{\text { Install.Cost }[€ / k W h]}{\operatorname{DoD}[\%] \cdot \text { cycles }}
$$

The basic idea about the optimization is to increase the HESS lifespan by loss minimization. For that reason, simple battery and supercapacitor models that account for the power losses are needed (Fig. 2).

For the battery case, the typical model based on series RC networks is simplified to a series resistance and a voltage source that corresponds to the open-circuit voltage, $V_{o c}$ (3) presented in Fig. 2. Altenatively, the efficiency given at the datasheet can be used. In our case, a value of $0.04 \Omega$ for all cases, and the equivalent one for all modules is computed considering the series and parallel number of cells $\left(n_{s}\right.$ and $n_{p}$ ) as in (2).

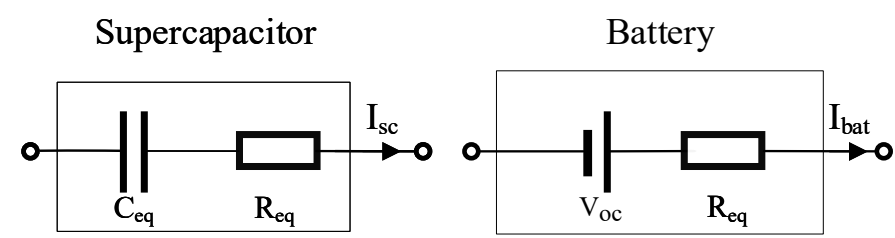

Fig. 2. Supercapacitor and battery model 
TABLE II

PARAMETERS OF THE SUPERCAPACITORS

\begin{tabular}{lccccc}
\hline SC & $\begin{array}{c}\mathbf{P}_{r} \\
{[\mathbf{k W}]}\end{array}$ & $\begin{array}{c}\mathbf{E}_{r} \\
{[\mathbf{W h}]}\end{array}$ & $\mathbf{V}[\mathbf{V}]$ & \multicolumn{2}{c}{$\begin{array}{c}\text { Install. Cost } \\
{[€ / \mathbf{k W h}]}\end{array}[€ / \mathbf{k W}]$} \\
\hline$S C_{1}$ & 69 & 70 & 62 & 17047 & 17 \\
$S C_{2}$ & 89 & 57 & 48 & 17907 & 18 \\
$S C_{3}$ & 44 & 52 & 48 & 19270 & 19 \\
\hline
\end{tabular}

TABLE III

HESS MODEL.

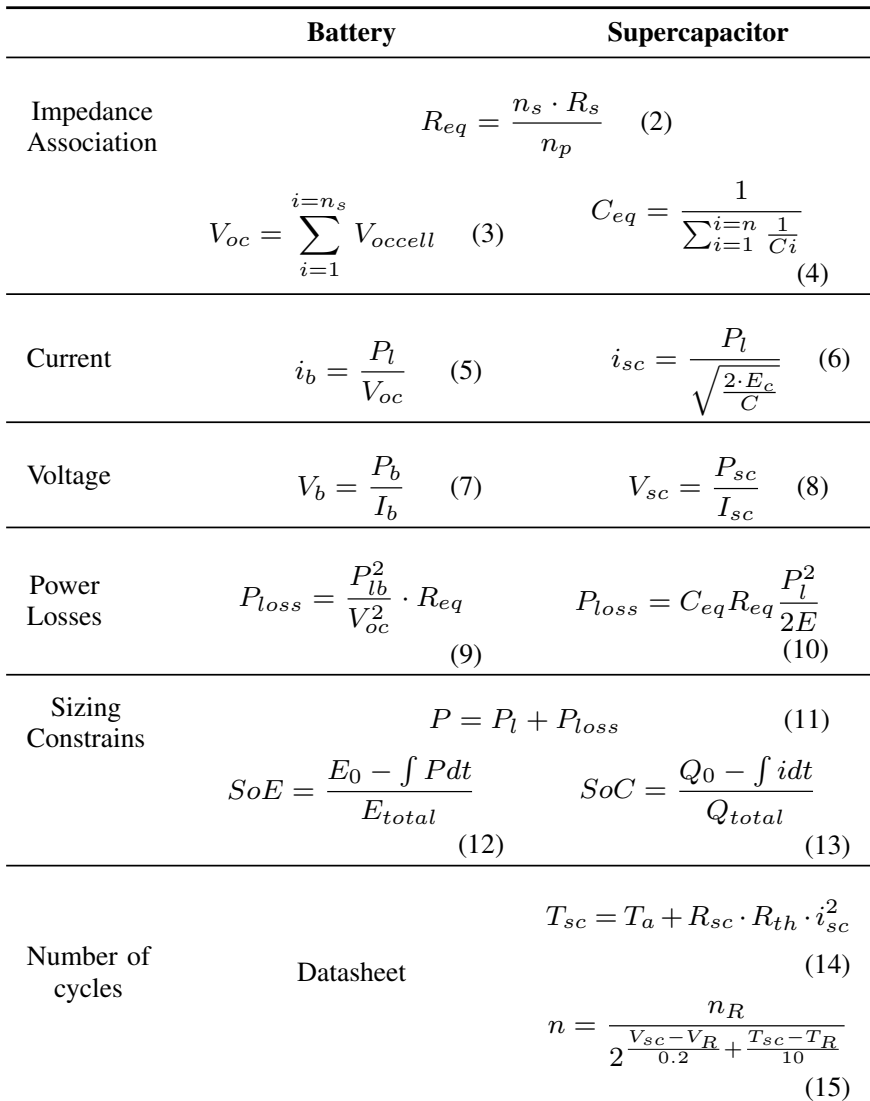

The operation range is assumed to be between 10 to $90 \%$ SoC, and it is considered the $V_{o c}$ to remain constant within this interval. On the other hand, the datasheet provides the energy, power and cycling constrains when performing a DoD up to an $80 \%$, which is considered the maximum one for the batteries. The number of batteries is sized to accomplish all the technical constrains. For that propose, $(9,11,12)$ are used, where $P$, $P_{l o s s}$ and $P_{l}$ are the power given by the storage, the losses and the load profile power; $S o E$ the state of energy and $E_{0}$ and $E_{\text {total }}$ the initial and total energy. For this kind of application, the equivalent parameters for the typical association of the batteries are already given by the manufacturer (Table I).

The supercapacitor model consists of an ideal capacitance and a series resistance as shown in Fig. 2. For sizing purposes, this model is accurate enough, and also, the parameters needed are provided in the data sheet [13]. The supercapacitors are grouped in series modules reaching $400 \mathrm{~V}$. The equivalent

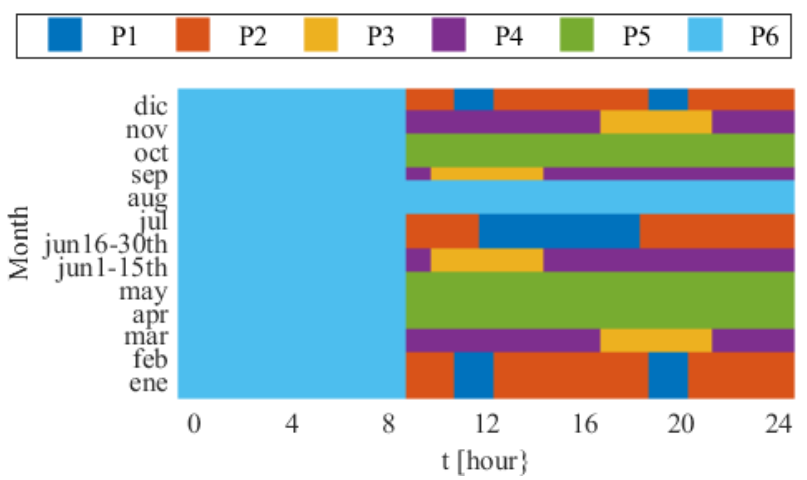

Fig. 3. Period distribution along the day each month, going from the most expensive 1 (P1) to the cheapest one (P6).

resistance and capacitance for each series modules grouped are gathered in $(2,4)$. The charge evolution and power constrains are calculated using (6),(10)-(15), where $i_{s c}$ and $V_{s c}$ are the current and voltage of the supercapacitor; $E$ is the available energy; $Q_{0}$ and $Q_{\text {total }}$ is the initial and total charge; $S o C$ the state of charge; $T_{s c}$ and $T_{a}$ the operating and ambient temperature; and $R_{s c}$ and $R_{t h}$ the electric and thermal resistance of one cell. Life cycling estimation is estimated by the empiric relationship shown in (15), where $n$ is the number of cycles and the suffix $R$ indicates the referenced value. This expression is based on the voltage and temperature evolution obtained previously [10], [11], [13].

\section{Tariff}

The electric bill is usually formed by two main charges worldwide: electricity consumption and capacity demanded [14]. This paper follows the Spanish regulation, which includes the energy and capacity charge, as well as taxes. In general, energy depends on the time of the day at which the consumption is required. For the specific considered case, sixperiod tariff is considered. Prices are shown in Table IV and the period varies as shown in Fig. 3. A similar analysis can be carried out with different tariff distributions.

TABLE IV

SIX-PERIOD TARIFF.

\begin{tabular}{lcccccc}
\hline Tariff & P1 & P2 & P3 & P4 & P5 & P6 \\
\hline $\mathrm{C}_{p}^{1} \in / \mathrm{kW} / \mathrm{year}$ & 11.29 & 10.52 & 9.93 & 9.25 & 8.97 & 6.90 \\
$\mathrm{C}_{e}^{2} \in / \mathrm{kWh}$ & 0.124 & 0.113 & 0.098 & 0.089 & 0.085 & 0.071 \\
\hline
\end{tabular}

${ }^{1} \mathrm{C}_{c}$ : Contracted capacity charge. ${ }^{2} \mathrm{C}_{e}$ : Energy consumption charge.

Each period can have a different contracted capacity, but the regulation states that each contracted capacity has to be equal or greater than the previous one $\left(P_{n+1} \geq P_{n}\right)$. Once the contracted capacity is settled for each period, the contracted capacity charge (CCC) is calculated using (16), where $P_{f i}$ is the contracted capacity in period $i$ expressed in $\mathrm{kW}$ and $C_{p i}$ is its annual price in period $i$. The energy charge (EC) is computed following (17), where $E_{i}$ is the energy consumed 


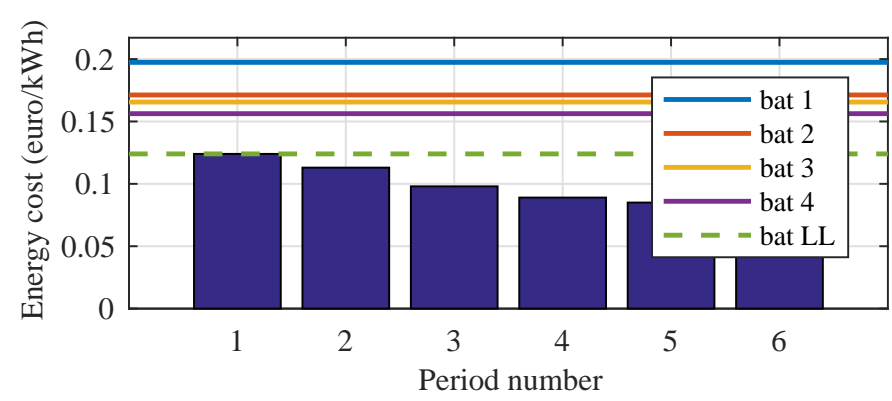

Fig. 4. Energy cost of each battery chemistry considering their lifespan compared to the grid energy charge. The dashed line highlights the upper limit price for making load levelling profitable.

in the period $i$ (expressed in $\mathrm{kWh}$ ) and $C_{e i}$ is the price of the energy in that period $i$.

$$
C C C=\sum_{j=1}^{i=n} C_{p i} P_{f i} \quad \text { (16) } \quad E C=\sum_{i=1}^{i=n} E_{i} C_{e i}
$$

Once $\mathrm{CCC}$ and EC are calculated, the total electricity bill cost is given by (18).

$$
E_{\text {cost }}=(C C C+E C)\left(1+E_{\text {tax }}\right)\left(1+V A T_{\text {tax }}\right)
$$

For the specific case considered, the VAT tax is $21 \%$, the electricity tax $\left(\mathrm{E}_{\operatorname{tax}}\right)$ is $5.11 \%$.

Considering the energy cost of all the battery models ( $E_{\text {cost }}$ listed in Table I) is above the cost of grid energy (Table IV), it is not profitable to size a HESS for shifting energy purposes (Fig. 4). It is worth also noting the special case of regenerative loads. Under the same consideration, once the HESS is completely charged, it is cheaper to return the energy back to the grid rather than increase the HESS energy capacity. However, this could be different based on local regulations (net-tariff). Hence, at the inflection point where the energy battery price falls below the upper price of a tariff as shown in Fig. 4, energy shifting will start to be profitable as a DSM measure. However, this energy cost is a function of the DoD, the number of cycles and the installation cost. The actual paper, only considers the existing battery models, being objective of future research the analysis of these coefficients when energy shifting strategies are adopted.

Considering all the above, the HESS will be sized to optimize the contracted service capacity by a peak-shaving strategy. In the case an exceed of stored energy is available at the end of the highest cost period, it will be used for reducing the demanded grid energy.

\section{Converter Impact}

The proposed sizing methodology also evaluates the impact of the power converter efficiency. Converter efficiency depends on the conduction and switching losses. In order to have a model approximation suitable to be considered in the optimization process, (19) is considered instead [15].

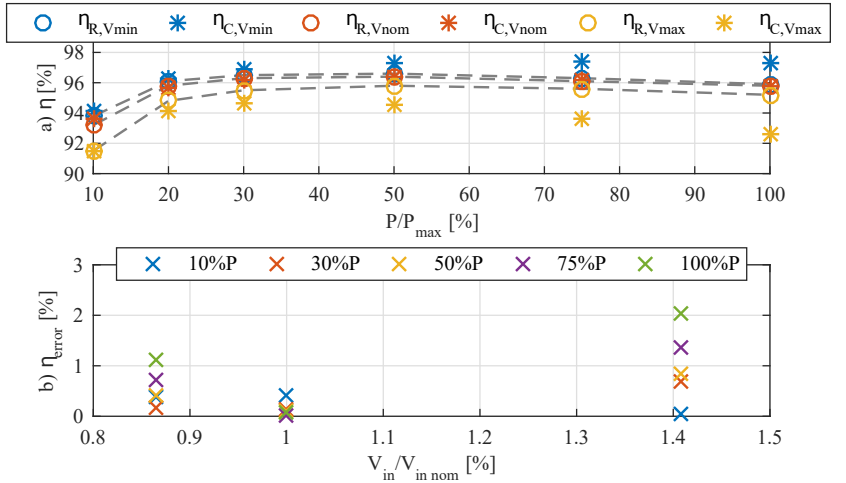

Fig. 5. $100 \mathrm{~kW}$ Converter efficiency example.a) Real $\left(\eta_{R}\right)$ and calculated $\left(\eta_{C}\right)$ efficiency at different input voltage $\left(v_{i n}\right)$ b) Resulting error of the efficiency calculated with (19) of a $100 \mathrm{~kW}$ at different input voltage of power.

$$
\begin{aligned}
P_{\text {loss }}= & \left(b_{0}+b_{1}\left(v_{i n}-1+b_{2}\left(\frac{1}{v_{\text {in }}}-1\right)\right)\right) \\
& +\left(b_{3}+b_{4}\left(v_{\text {in }}-1\right)+b_{5}\left(\frac{1}{v_{i n}}-1\right)\right) p_{i n} \\
& +\left(b_{6}+b_{7}\left(v_{i n}-1\right)+b_{8}\left(\frac{1}{v_{i n}}-1\right)\right) p_{i n}^{2}
\end{aligned}
$$

where $v_{i n}$ and $p_{i n}$ are the input voltage and input power; and $b_{x}$ are the coefficients that have already been calculated based on the converter efficiency data provided by the California Energy Commission [16]. Losses mainly come from the auxiliary circuits and drives (independent of power); voltage drops, ohmic losses and switching losses, related to the power load; and other losses related to the input voltage [12], [15]. Fig.5a depicts the efficiency curve from the data [16] and the one obtained using (19) at minimum, nominal and maximum input voltage for a $100 \mathrm{~kW}$ converter. The efficiency estimation error is always below $3 \%$ as shown in Fig.5b for all efficiency and voltage ranges. Table $\mathrm{V}$ gives the efficiency of some of the converters considered at different power levels. The higher the power, the higher the overall efficiency. The converter cost is considered to be $100 € / \mathrm{kW}$.

TABLE V

CONVERTER EFFICIENCY RESULTS AT 100, 500 AND $1000 \mathrm{KW}$.

\begin{tabular}{lccccc}
\hline $\begin{array}{c}\mathbf{P}_{\text {conv }} \\
{[\mathbf{k W}]}\end{array}$ & $\begin{array}{c}\eta_{10 \%} \\
{[\mathbf{\%}]}\end{array}$ & $\begin{array}{c}\eta_{30 \%} \\
{[\boldsymbol{\%}]}\end{array}$ & $\begin{array}{c}\eta_{50 \%} \\
{[\boldsymbol{\%}]}\end{array}$ & $\begin{array}{c}\eta_{75 \%} \\
{[\%]}\end{array}$ & $\begin{array}{c}\eta_{100 \%} \\
{[\%]}\end{array}$ \\
\hline 100 & 90.3 & 94.9 & 95.2 & 95 & 94.4 \\
500 & 95.8 & 97 & 96.8 & 96.2 & 95.5 \\
1000 & 97 & 98.1 & 98.1 & 98 & 97.6 \\
\hline
\end{tabular}

\section{ANALYSIS AND HESS Optimization Method}

\section{A. Digital signal processing}

The proposed optimization method allocates the power by using digital filtering techniques over the consumption 
profiles. [17]. The HESS operation will be targeted for peak shaving during the tariff high cost periods. The higher the power carried by the HESS is, the higher the revenue and the installations costs. This duality triggers the need for an optimization method. In the flow chart presented in Fig. 6, the main idea is explained. The data has been recorded using a sample time of $1 \mathrm{~s}$. The analysis is carried out in three steps. First, the peak shaving level is decided and the profile to be given by the HESS is determined using the histogram distribution. Secondly, it is obtained the profile that has to be handled by the HESS in the time domain to reduced the capacity. Finally, the power shared between the batteries and the supercapacitors is selected, so the ratio of energy is the same than the installation cost of the required energy by each element. An iterative process compromising frequency domain analysis for the selection of the cut-off frequency for the sharing filter and time domain for calculating the corresponding energy share is used.

The power handled by the HESS is allocated by using two complementary high-pass and low-pass filters. The high-pass filter and low-pass filter provide the power to the supercapacitors and the batteries respectively. Fig. 7 shows an example. In the upper graph, it is shown the load profile and the power provided by the grid, which has been reduced at high cost periods. The lower graph shows the power demanded to the HESS. As it can be seen, the supercapacitors handle the peak powers, whereas the batteries operate at lower power and higher energy levels.

Fig. 8 collects the energy distribution of the first profile case in a histogram during the day. It can be shown that the energy content at high power levels is very low, thus enabling to perform a peak shaving at high cost periods. Besides, the profile keeps periodic along the day to ensure the HESS would be able to provide the power demanded and avoid penalizations. Fig. 9 provides the energy distribution for all the processes. It is clear that all the three have in common a low-energy value in the high-power region.

Based on the HESS power and energy pricing, an initial cut-off frequency $f_{c}$ can be selected for the power share within the supercapacitors and batteries. Considering the costs breakdown in Table I and II, it is shown that the difference between energy price is much more relevant than the power one. Besides, as it is shown in Fig. 10, the required energy installation for a given power allocation is much higher. Based on that, only the energy factor $k_{E}(20)$ is considered for the selection of $f_{c}$, where $E_{b}$ and $E_{s c}$ is the energy required of each technology. On the contrary, $k_{P H E S S}$ gathers the economical relation of both technologies taking into account the battery $\left(P_{b}\right)$ and supercapacitor $\left(P_{s c}\right)$ energy price collected in Table I and II.

$$
k_{E}=\frac{E_{b}}{E_{s c}+E_{b}} \quad(20) k_{P H E S S}=\frac{P_{s c}}{P_{b a t}+P_{s c}}
$$

Fig. 11 depicts the variation of $k_{E}$ for the three analysed process and its relation with $k_{P H E S S}$ in function of the cutoff frequency of the sharing filter, $f_{c}$. The intersection point

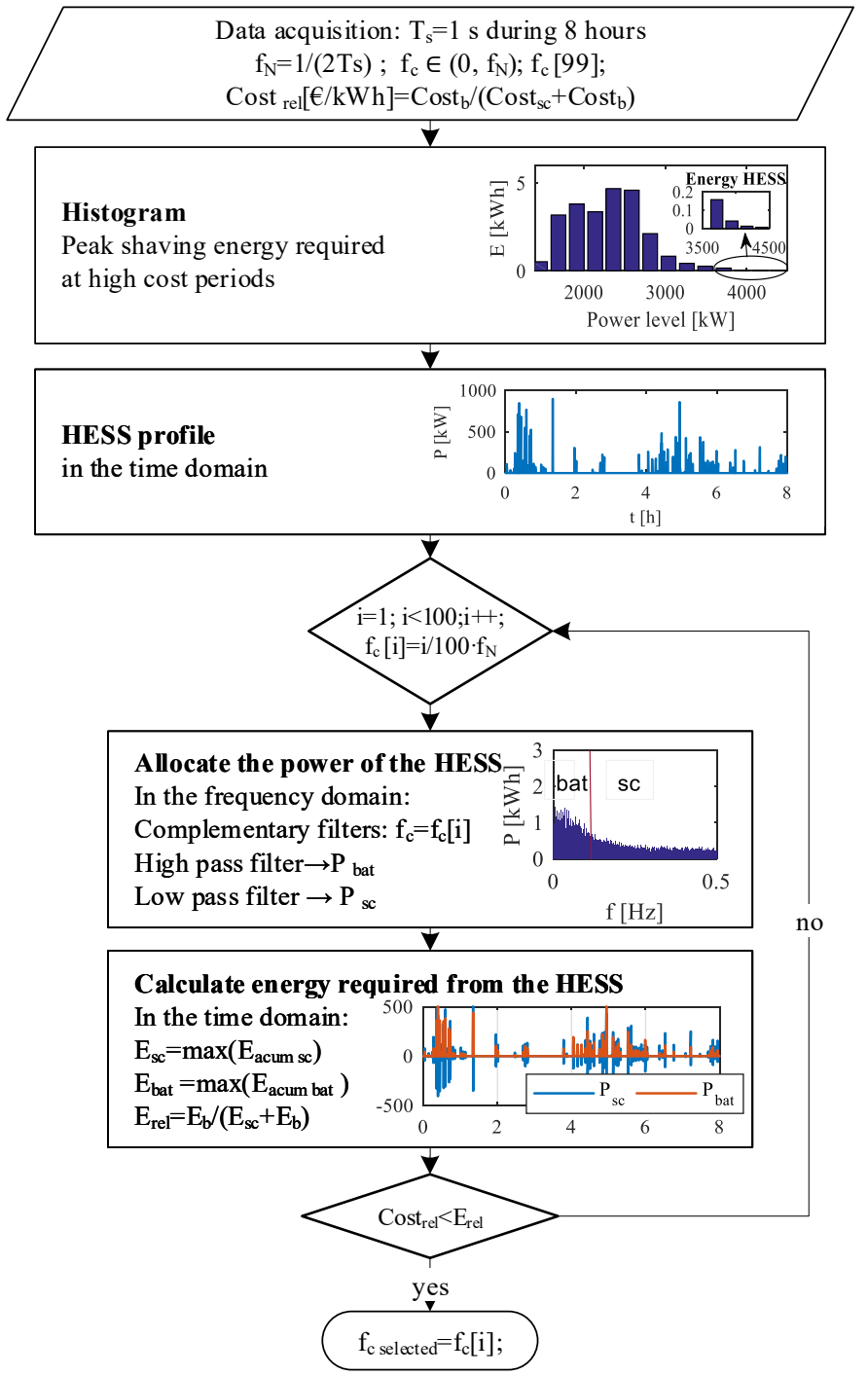

Fig. 6. Data analysis process steps: 1. Decide the peak shaving level. 2 . Get the HESS profile. 3.Perform the frequency domain analysis of the HESS profile and select power allocation.

between the $k_{E}$ curves and the $k_{P H E S S}$ value determines the $f_{c}$ value. The three processes are evaluated for a peak shaving of $500 \mathrm{~kW}$. There is one process $(P-3)$ that does not intersect with $k_{P H E S S}$. For this special case, the HESS will be formed only of batteries as a first approach.

Up to this point, a procedure for the selection of the sharing energy between the batteries and the supercapacitors for a given power shaving level has been shown. However, the selection of the optimal power level is still undecided. The main idea about the optimization is to realize that the HESS energy requirements for each peak shaving level determines the opportunity cost for the HESS. This can be analysed by the curves shown in Fig. 10. In there, the logarithmic relationship between peak shaving and the HESS energy requirements for the installation is depicted. The lower the energy required, the higher the revenue. 

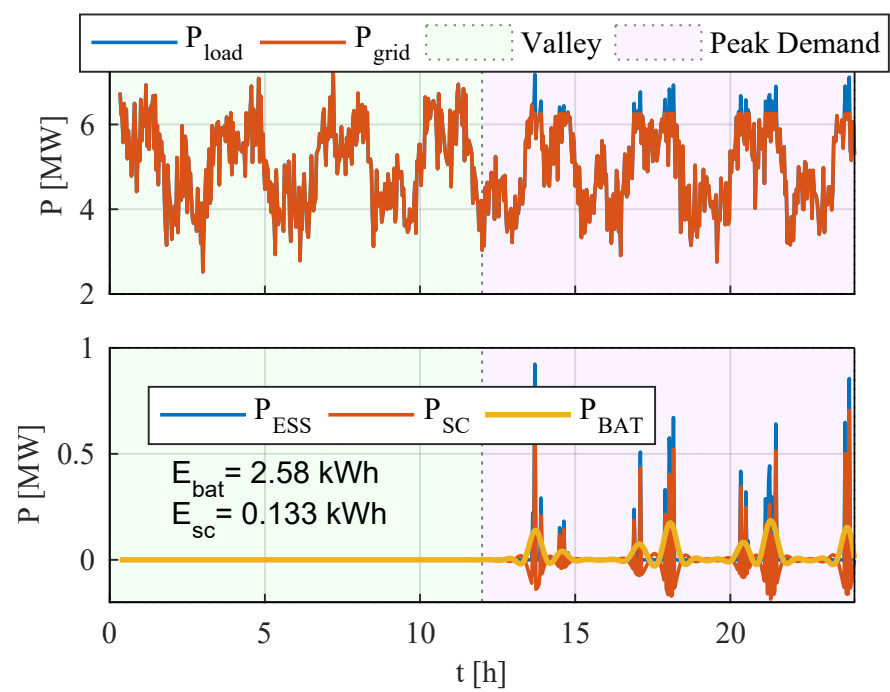

Fig. 7. Power allocation example. a) Load and grid power optimized. b) HESS, supercapacitor and battery power.

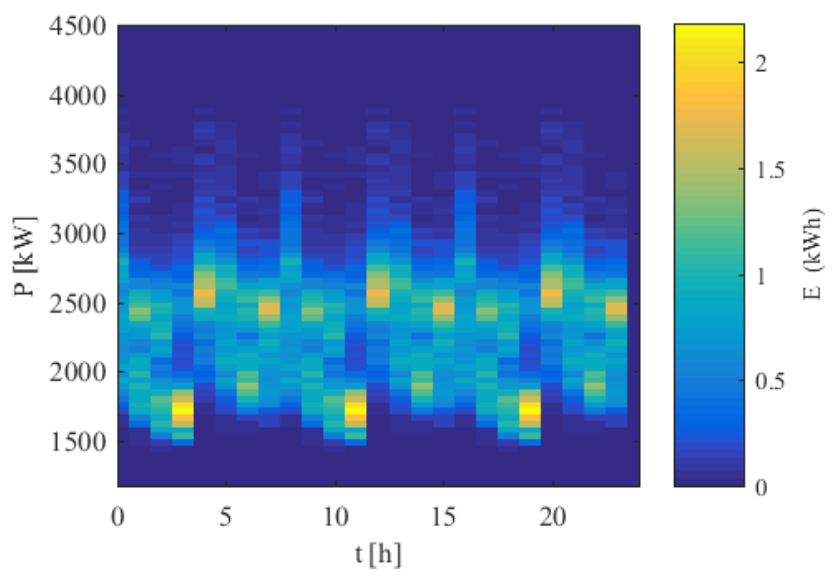

Fig. 8. Histogram of the energy distribution of the profile $P-1$.
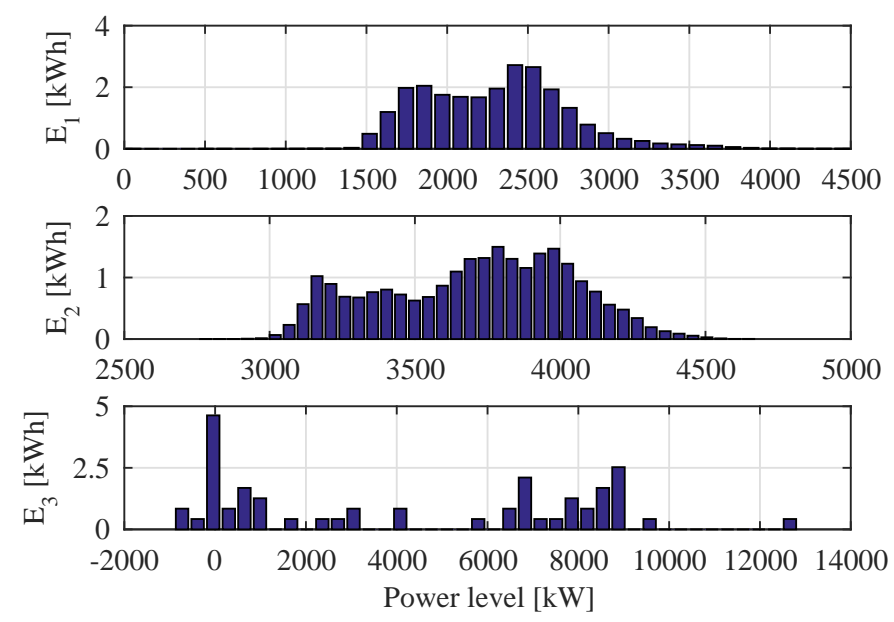

Fig. 9. Histogram of the energy distribution of $P-1, P-2$ and $P-3$ based on the power level.

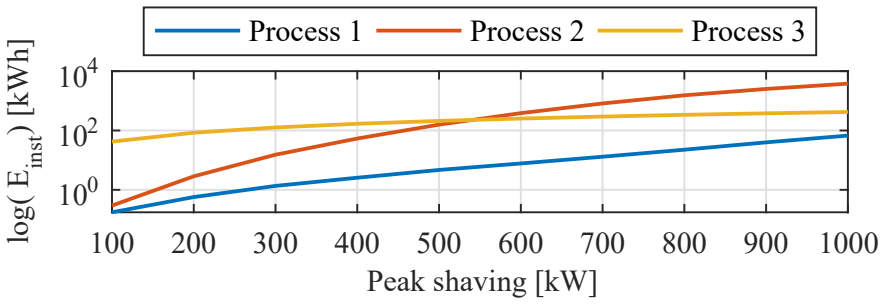

Fig. 10. Energy requirements of the HESS at different peak shaving levels.

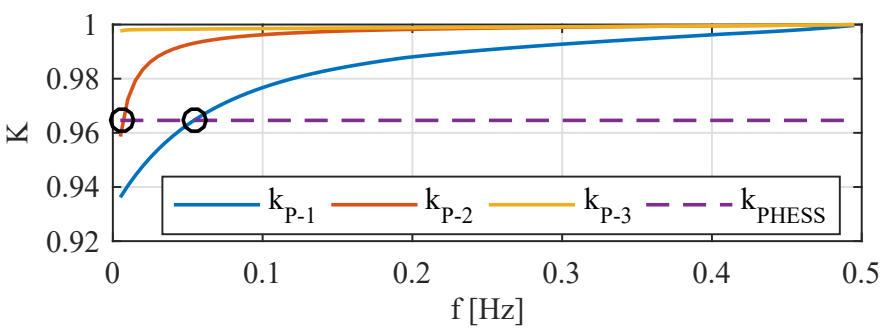

Fig. 11. Variation on energy allocation $k_{E}$ with $f_{c}$ and optimum economic relation $k_{H E S S}$. The intersection of the curves highlighted corresponds to the initial $f_{c}$ of each process.

\section{B. Optimization method}

The net present value (NPV) and the payback period are the main metrics evaluated by the method. NPV is defined in (22); where $C_{t}$ is the net cash flow during period $t, C_{0}$ the initial investment cost, $r$ the discount rate, which is considered $1 \%$, and $t$ the number of periods during the HESS life [18]. It gives the net present value of a varying cash flow and is the parameter to be maximized in the method.

$$
N P V=\sum_{t=1}^{T} \frac{C_{t}}{(1+r)^{t}}-C_{o}
$$

Fig. 12 presents an example of the evolution of these economic factors with respect to the performed peak shaving. The greater the peak shaving, the larger the installation, and the higher the savings obtained from reducing the electricity bill. The NPV will be maximized at a peak shaving level, which is the solution to be founded by the method. For the same peak shaving level, the installation cost varies with the hybridization ratio between supercapacitors and batteries. Besides, it is given a $10 \%$ of margin between the maximum power contracted and the expected maximum power demanded to the grid to avoid penalizations by the electricity trader.

The total amount of modules should be the minimum number of modules that accomplishes the technical constrains. Thus, the final solution is the one that has a HESS which ensures the lifespan required to achieve the maximum NPV possible. However, a further evaluation should be considered for getting this maximum NPV as the best option. As shown in Fig. 12, the NPV value remains almost constant at its maximum for a wide range of power installed. Thus, it might be a better solution to slightly reduce the NPV value and perform a lower peak shaving with lower requirements in the installed HESS power. 


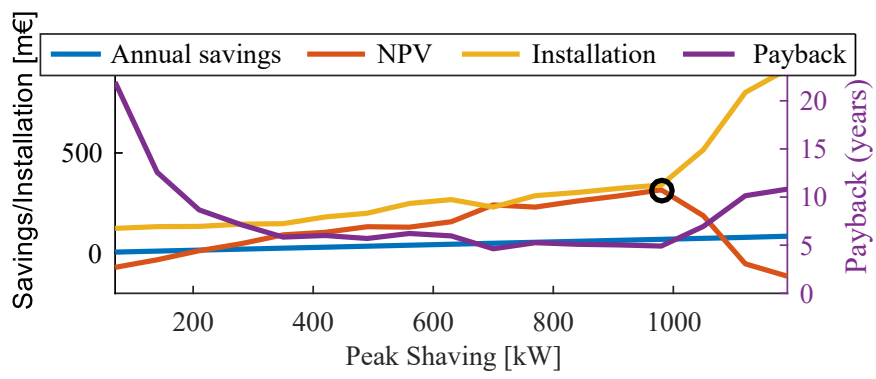

Fig. 12. Example of the variation of the economic factors with the power installed. The highlighted point locates the optimum point.

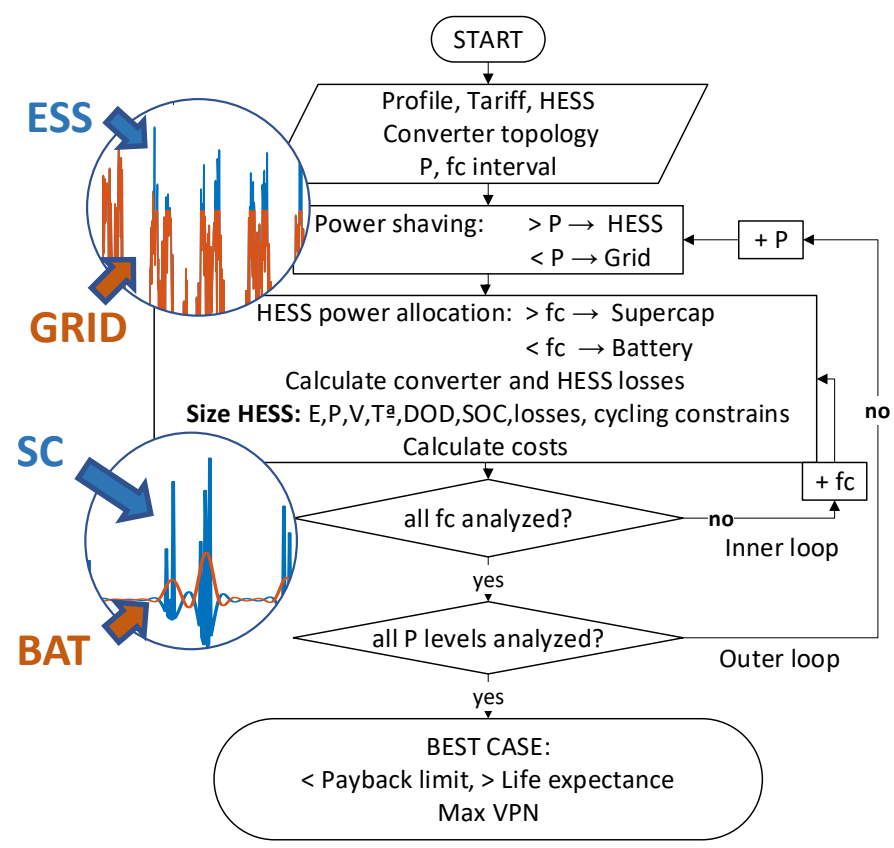

Fig. 13. Optimization method flow chart.

Fig. 13 depicts the scheme of the optimization method. The inputs are: the profile to be analysed, the tariff and the battery and supercapacitor models. The optimization method is mainly composed of two sequentially-connected iterative loops: an outer loop where different power levels of peak shaving are evaluated and an inner loop where the power sharing allocation between the supercapacitors and the battery is analysed for each power level and the HESS is sized. The power sharing is optimized by varying the cut-off frequencies of two complementary filters.

After deciding the power allocation, the converter is sized and the power losses are included. For this work, a typical configuration of two bidirectional synchronous dc-dc boost converter (one for each technology) and a dc-ac inverter for the grid interface is used. The size of the dc-ac power converter will be picked to match the maximum power demanded from the HESS, whereas the dc-dc will match the maximum power of each technology. The resulting power losses, calculated according to (19), are included to get the new power demanded to the HESS.
The HESS is sized so it can handle the power demanded with the lower number of devices possible. During the periods that the HESS do not operate, the supercapacitors remain at half the nominal voltage. A completely discharge will result in a shorten lifespan [19]. For the same reason, the voltage will be kept within the limits during operation [3].

For sizing the battery is performed a daily discharge with a DoD of $80 \%$. The energy, power, DoD and cycling constrains (Table I) are considered for the sizing proposes.

\section{RESUlts}

This section provides the optimization sizing results for the selection of the optimal $f_{c}$ with the procedure explained in Fig. 13. The results are compared with the HESS sizing obtained before the optimization, following the straightforward methodology proposed in Fig. 6 based on the energy cost of each technology. Results are presented for all the processes shown in Fig. 1. The system lifespan should be above 10 years and the payback should be below 6 years.

The results without and with the proposed optimization are shown in Tables VI and VII. Some important conclusions can be grabbed from the data: 1) The optimization method makes two of the processes $(P-1$ and $P-2)$ to be profitable, whereas only $P-1$ is suitable using the initial cut-off frequency selection, achieving a lower NPV. 2) In $P-1$, the increase in the NPV and the reduction in the payback are $31 \%$ and $30 \%$ respectively when the optimization method is applied, 3) Up to near $1 \mathrm{MW}$ of peak shaving is achieved, representing the $21 \%$ of the total installation power. 4) $P-3$ requires a greater amount of energy installation for performing a peak shaving (Fig. 10), making the process non profitable.

As an example for the optimization curves, Fig. 14 depicts the surface that presents all NPV and payback period cases for $P-1$. The best case is the maximum point of the Fig. 14a, whereas the lower payback period is highlighted in Fig.14b.

TABLE VI

RESULTS WITHOUT OPTIMIZING THE POWER ALLOCATION.

\begin{tabular}{lccc}
\hline Process & $\mathbf{1}$ & $\mathbf{2}$ & $\mathbf{3}$ \\
\hline NPV $[\mathrm{k} €[$ & 227.6 & $\mathrm{NP}^{1}$ & $\mathrm{NP}^{1}$ \\
Payback [years] & 5.6 & & \\
Savings[k€/years] & 59.4 & & \\
Installation [k€/kWh] & 334.7 & & \\
Technology used & $1 \mathrm{LFP}_{c y l}$ & & \\
$\mathbf{f}_{c}[\mathrm{~Hz}]$ & $+20 \mathrm{SC}_{1}$ & & \\
$\mathbf{P}_{\text {shaving }}[\mathrm{kW}]$ & 0.055 & & \\
\hline
\end{tabular}

${ }^{1}$ Non profitable - Negative NPV.

\section{CONCLUSION}

This paper has presented an optimization method for HESS sizing considering technical and economical constraints. The HESS design is based on different battery chemistries and supercapacitors. The optimization method is focused on cyclic consumption profiles, which are often the case in industrial 
TABLE VII

RESULTS OPTIMIZING THE POWER ALLOCATION.

\begin{tabular}{lccc}
\hline Process & $\mathbf{1}$ & $\mathbf{2}$ & $\mathbf{3}$ \\
\hline NPV $[\mathrm{k} €[$ & 328 & 63.8 & $\mathrm{NP}$ \\
Payback [years] & 4.3 & 6.9 & \\
Savings[k€/years] & 63.9 & 25.2 & \\
Installation [k€/kWh] & 276.8 & 174.9 & \\
Technology used & $1 \mathrm{LFP}_{\text {pris }}$ & $1 \mathrm{NMC}$ & \\
$\mathbf{f}_{c}[\mathrm{~Hz}]$ & $+46 \mathrm{SC}_{1}$ & $+5 \mathrm{SC}_{1}$ & \\
$\mathbf{P}_{\text {shaving }}[\mathrm{kW}]$ & $5 \cdot 10^{-4}$ & 0.16 & \\
\hline
\end{tabular}
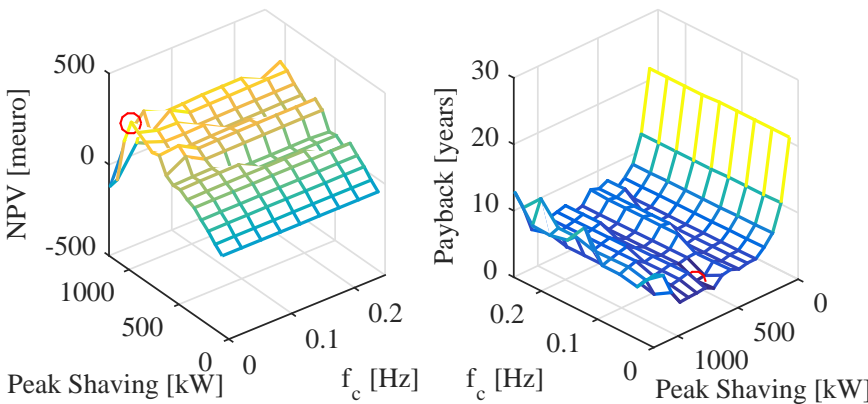

Fig. 14. NPV and payback period for all cases studied in Process 1.

applications. The technical constraints include an analysis of the HESS losses, considering the battery and supercapacitor losses as well as the converter efficiency. Simple models have been used, suitable for be considered in the optimization method. From the economical side, the tariff distribution between energy and power as well as metrics regarding the installation costs, the payback and the NPV are considered. The design of the HESS is based on the selection of the optimal cut-off frequency for the profile share between the battery and the supercapacitor. An stadistical approach based on the analysis of the consumption profile has been developed. The optimization method is compared with respect to a nonoptimal sizing relying only on economical constraints. A significant reduction of $30 \%$ is achieved in the payback and an increase of $31 \%$ in the NPV when the optimization method is considered.

\section{REFERENCES}

[1] R. Hidalgo-León, D. Siguenza, C. Sanchez, J. León, P. Jácome-Ruiz, J. Wu, and D. Ortiz, "A survey of battery energy storage system (bess), applications and environmental impacts in power systems," in 2017 IEEE Second Ecuador Technical Chapters Meeting (ETCM), Oct 2017, pp. 16.

[2] J. S. Goud, S. Tunga, Q. Sultana, and S. Bindu, "Li-ion based optimally sized grid interfaced roof top pv system," in 20163 rd International Conference on Electrical Energy Systems (ICEES), March 2016, pp. 267-271.

[3] M. Uno and K. Tanaka, "Accelerated ageing testing and cycle life prediction of supercapacitors for alternative battery applications," in 2011 IEEE 33rd International Telecommunications Energy Conference (INTELEC), Oct 2011, pp. 1-6.

[4] P. K. S. Roy, H. B. Karayaka, Y. Yan, and Y. Alqudah, "Size optimization of battery-supercapacitor hybrid energy storage system for $1 \mathrm{mw}$ grid connected pv array," in 2017 North American Power Symposium (NAPS), Sept 2017, pp. 1-6.
[5] P. R. Babu and K. A. Kumar, "Application of novel dsm techniques for industrial peak load management," in 2013 International Conference on Power, Energy and Control (ICPEC), Feb 2013, pp. 415-419.

[6] B. Hartmann and S. Liptk, "Development of steady state and dynamic energy storage models for digsilent powerfactory," in 2015 IEEE Eindhoven PowerTech, June 2015, pp. 1-6.

[7] dSPACE, "https://www.dspace.com/en/pub/home/products/systems/ simulationmodels/researchandeducation/asm_forschungsprojekte/toolbox speichersyste.cfm," dSPACE, Tech. Rep., 2018.

[8] K. Okedu and R. Uhunmwangho, "Optimization of renewable energy efficiency using homer," InternationalJournal of Renewable Energy Research, vol. 4, no. 4, pp. 421-427, 2013.

[9] J. Mei, E. K. W. Cheng, and Y. C. Fong, "Lithium-titanate battery (lto): A better choice for high current equipment," in 2016 International Symposium on Electrical Engineering (ISEE), Dec 2016, pp. 1-4.

[10] D. B. Murray and J. G. Hayes, "Cycle testing of supercapacitors for long-life robust applications," IEEE Transactions on Power Electronics, vol. 30, no. 5, pp. 2505-2516, May 2015.

[11] Skeleton, "White paper: Ultracapacitor voltage, temperature, and lifetime," Skeleton Technologies. Available in www.skeletontech.com, Tech. Rep., 2016.

[12] F. H. Dupont, J. Z. Bertomeu, C. Rech, and J. R. Pinheiro, "Mathematical efficiency modeling of static power converters," in 2015 IEEE 13th Brazilian Power Electronics Conference and 1st Southern Power Electronics Conference (COBEP/SPEC), Nov 2015, pp. 1-6.

[13] T. Kovaltchouk, B. Multon, H. B. Ahmed, J. Aubry, and P. Venet, "Enhanced aging model for supercapacitors taking into account power cycling: Application to the sizing of an energy storage system in a direct wave energy converter," in 2014 Ninth International Conference on Ecological Vehicles and Renewable Energies (EVER), March 2014, pp. $1-10$.

[14] T.Yamada, "International comparison of electric service tariffs," IEEJ, 2002.

[15] A. Driesse, P. Jain, and S. Harrison, "Beyond the curves: Modeling the electrical efficiency of photovoltaic inverters," in 2008 33rd IEEE Photovoltaic Specialists Conference, May 2008, pp. 1-6.

[16] C. E. Comission, "http://www.gosolarcalifornia.ca.gov," California Energy Comission, Tech. Rep., 2018.

[17] L. Sun, N. Zhang, M. Awadallah, and P. Walker, "An innovative control strategy for a hybrid energy storage system (hess)," in 2017 IEEE International Conference on Mechatronics (ICM), Feb 2017, pp. 434439.

[18] W. Wetekamp, "Net present value (npv) as a tool supporting effective project management," in Proceedings of the 6th IEEE International Conference on Intelligent Data Acquisition and Advanced Computing Systems, vol. 2, Sept 2011, pp. 898-900.

[19] R. German, A. Sari, O. Briat, J. M. Vinassa, and P. Venet, "Impact of voltage resets on supercapacitors aging," IEEE Transactions on Industrial Electronics, vol. 63, no. 12, pp. 7703-7711, Dec 2016. 